\title{
PENGARUH MOTIVASI DAN KOMPENSASI TERHADAP KINERJA KARYAWAN PADA CV. JAYA BAKERY DI BANDAR LAMPUNG.
}

\author{
Ardansyah $^{1}$, Yunita Pratama \\ Fakultas Ekonomi dan Bisnis, Universitas Bandar Lampung \\ Jl. ZA Pagar Alam No. 26. Labuhan Ratu, Bandar Lampung. \\ Email : ardansyah@ubl.ac.id; yunita.15011053@student.ubl.ac.id
}

\begin{abstract}
ABSTRAK
Permasalahan yang dirumuskan adalah, Apakah Motivasi berpengaruh terhadap kinerja karyawan, Apakah kompensasi berpengaruh terhadap kinerja karyawan, Apakah Motivasi dan kompensasi secara bersama-sama berpengaruh terhadap kinerja karyawan. Tujuan dalam penelitian adalah Untuk menganalisis menurunnya kinerja karyawan CV Jaya Bakery yang dipengaruhi oleh Motivasi dan kompensasi, dan Sebagai sumbangan pemikiran kepada pihak perusahaan dalam rangka berusaha meningkatkan kinerja karyawan. Populasi dalam penelitian adalah karyawan di CV Jaya Bakery yang berjumlah 40 orang responden. Pengumpulan data menggunakan kuesioner. Uji validitas dan realibelitas dalam penelitian menggunakan Spss versi 17 berstatus valid dan reliabel. Metode yang digunakan adalah Regresi linier berganda, Uji t dan Uji F. Hasil analisis Regresi linier berganda yaitu: Y= $9,609+0,435 \mathrm{X} 1+0,315 \mathrm{X} 2$. Pengujian Hipotesis Motivasi terhadap kinerja karyawan dengan taraf signifikansi $5 \%$ yaitu $\mathrm{dk}=\mathrm{n}-\mathrm{k}$ maka $\mathrm{dk}=40-3=37$, thitung 3,847 $>\mathrm{t}_{\text {tabel }} 2,026$ artinya $\mathrm{H}_{a}$ diterima dan $\mathrm{H}_{0}$ ditolak, artinya terdapat pengaruh yang positif dan signifikan antara variabel Motivasi dengan kinerja karyawan. Pengujian Hipotesis kompensasi terhadap kinerja karyawan dengan taraf signifikansi 5\% terdapat pengaruh antara Motivasi dengan kinerja karyawan. Pengujian Hipotesis $F$ dengan taraf $5 \%$ yaitu $F$ hitung $(38,917)>F$ tabel $(3,32)$, artinya $\mathrm{H}_{\mathrm{o}}$ ditolak dan $\mathrm{H}_{\mathrm{a}}$ diterima. Artinya Motivasi dan Kompensasi secara bersamasama berpengaruh terhadap Kinerja Karyawan. Dengan demikian hipotesis penelitian yang dinyatakan dalam penelitian ini dapat diterima, berarti variabel Motivasi dan kompensasi berpengaruh terhadap kinerja karyawan di CV Jaya Bakery.
\end{abstract}

Kata Kunci: Motivasi, Kompensasi, dan Kinerja Karyawan. 


\section{PENDAHULUAN}

\section{Latar belakang}

Sumber daya manusia merupakan aspek yang dinamis dan mempunyai kemampuan untuk berkembang. Salah satu bagian terpenting yang berperan dalam menentukan keberhasilan perusahaan adalah dengan pembinaan tenaga kerja yang potensial. Perusahaan berusaha mencari dan membina karyawan dengan semangat tinggi, menciptakan dan memelihara keunggulan sumber daya manusia yang mampu bersaing.

Tercapainya tujuan perusahaan adalah keterkaitan hubungan antara perusahaan dengan karyawan dimana kedua hal ini harus berjalan secara harmonis. Karyawan akan berkontribusi sesuai dengan wewenang dan tanggung jawab yang telah diberikan demi tercapainya keberhasilan perusahaan, kontribusi tersebut merupakan perwujudan aktualisasi dari kinerja karyawan dan tidak menutup kemungkinan juga sebagai peluang untuk memenuhi kebutuhan hidupnya. Kinerja karyawan akan membawa dampak bagi karyawan yang bersangkutan maupun perusahaan.

Dalam meningkatkan kinerja karyawannya perusahaan akan melakukan beberapa cara yang dapat mendorong karyawan untuk bekerja secara maksimal. Beberapa kegiatan tersebut diantaranya pemberian pelatihan, pemberian kompensasi, pemberian penghargaan dan lain sebagainya. Kegiatan tersebut akan sangat berkaitan dengan pemberian kompensasi. Kepuasan atas kompensasi dapat mempengaruhi perilaku karyawan untuk bekerja lebih bersemangat dan memacu tingginya kinerja.

Motivasi menjadi salah satu faktor pendorong kinerja karyawan. Motivasi sebagai proses yang menjelaskan intensitas, arah dan ketekunan seorang individu untuk mencapai tujuannya. Motivasi merupakan faktor psikologis yang menunjukkan minat individu terhadap pekerjaan, rasa puas dan ikut bertanggung jawab terhadap aktivitas atau pekerjaan yang dilakukan. Perilaku seseorang pada umumnya dimotivasi oleh keinginan untuk memperoleh tujuan tertentu. Motivasi merupakan hal yang penting untuk diperhatikan, karena dengan motivasi seorang karyawan atau pegawai akan dapat memiliki semangat yang tinggi dalam melaksanakan tugas yang dibebankan. Tanpa adanya motivasi maka seorang karyawan tidak dapat memenuhi tugas-tugasnya dengan baik, hasil kerja yang dihasilkan pun tidak akan memuaskan.

Kompensasi merupakan sesuatu yang diterima karyawan sebagai pengganti kontribusi jasa mereka pada perusahaan. Setiap karyawan dalam suatu organisasi mempunyai keinginan untuk mendapatkan kompensasi yang sesuai dengan harapan mereka. Apabila harapan tersebut terpenuhi, maka karyawan tersebut akan senantiasa bersemangat dalam bekerja. Departemen personalia merancang dan mengadministrasikan kompensasi karyawan. Apabila kompensasi yang diberikan sesuai, karyawan lebih terpuaskan dan termotivasi untuk mencapai sasaran organisasi.

CV Jaya Bakery merupakan produsen aneka roti dan kue terlaris di Kota Bandar Lampung. Tidak hanya Jaya Bakery masih banyak tempat yang menjual roti di Kota Bandar Lampung mulai dari Bobo Bakery, Bradtalk, Yussy Akmal, Shereen dan masih banyak lagi. Dalam upaya untuk memenuhi kebutuhan konsumen perusahaan khususnya roti seperti di CV Jaya Bakery tidak hanya mempertimbangkan operasi jangka pendek dan kebutuhan sesaat.

Fenomena yang terjadi dalam hal motivasi dan kompensasi, pada CV Jaya Bakery Bandar Lampung, para pemimpin berusaha memberikan motivasi terbaik dan kompensasi, namun hal tersebut masih belum cukup bagi karyawan CV Jaya Bakery Bandar Lampung. CV Jaya Bakery Bandar Lampung merupakan perusahaan yang memberikan bonus bagi karyawanya sesuai dengan kontribusi dan prestasinya, 
berikut ini daftar tunjangan karyawan pada CV Jaya Bakery Bandar Lampung.

Tabel 1.1

Daftar Tunjangan Karyawan CV Jaya Bakery Bandar Lampung Tunjangan

\begin{tabular}{|c|c|c|}
\hline \multicolumn{2}{|c|}{ Tunjangan } & \multirow{2}{*}{ Asuransi } \\
\cline { 1 - 2 } $\begin{array}{c}\text { Uang } \\
\text { Makan }\end{array}$ & Transport & \\
\hline 450.000 & 300.000 & 80.000 \\
\hline
\end{tabular}

Sumber : CV Jaya Bakery Bandar Lampung

Berdasarkan data di atas penetapan tunjangan yang dilakukan CV Jaya Bakery Bandar Lampung menurut hasil wawancara peneliti dengan salah satu karyawan bahwa tunjangan yang diberikan oleh CV Jaya Bakery tidak cukup untuk karyawan, dikarenakan tidak mencukupi untuk konsumsi ketika sedang lembur, dan tidak ada toleransi bagi karyawannya ketika sedang kelelahan.

Tabel 1.2 Kompensasi Karyawan Pada

CV Jaya Bakery Bandar Lampung

\begin{tabular}{|c|c|c|c|c|}
\hline $\begin{array}{l}\mathbf{N} \\
\mathbf{0}\end{array}$ & $\begin{array}{l}\text { Pendidi } \\
\text { kan } \\
\text { Karyaw } \\
\text { an } \\
\end{array}$ & $\begin{array}{c}\text { Jabatan } \\
\text { Staff }\end{array}$ & $\begin{array}{c}\text { Juml } \\
\text { ah }\end{array}$ & Gaji \\
\hline 1 & S2 & Manajer & 1 & $\begin{array}{c}5.000 . \\
000\end{array}$ \\
\hline 2 & S1 & $\begin{array}{c}\text { Staf } \\
\text { Keuanga } \\
n\end{array}$ & 4 & $\begin{array}{c}4.000 . \\
000\end{array}$ \\
\hline 3 & D3 & $\begin{array}{c}\text { Staf } \\
\text { Administ } \\
\text { rasi }\end{array}$ & 8 & $\begin{array}{c}2.800 . \\
000\end{array}$ \\
\hline 4 & D3 & $\begin{array}{c}\text { Staf } \\
\text { Marketin } \\
\mathrm{g}\end{array}$ & 8 & $\begin{array}{c}2.800 . \\
000\end{array}$ \\
\hline 5 & SMA & Baker & 5 & $\begin{array}{c}2.200 . \\
000\end{array}$ \\
\hline 6 & SMA & Sales & 14 & $\begin{array}{c}1.850 . \\
000\end{array}$ \\
\hline
\end{tabular}

Sumber : CV Jaya Bakery Bandar Lampung

Berdasarkan data di atas penetapan kompensasi yang dilakukan CV Jaya
Bakery Bandar Lampung dilakukan secara bertahap dan sesuai dengan jabatan serta prestasi dari karyawan dalam upaya menciptakan karyawan yang mampu bekerja sesuai keinginan perusahaan, peningkatan kompensasi yang diiringi dengan kenaikan jabatan dimaksudkan dalam upaya penciptaan kepuasan kerja terhadap kinerja yang diberikan karyawan. Indikasi yang menunjukkan rendahnya kinerja karyawan CV Jaya Bakery Bandar Lampung adalah berdasarkan data yang penulis peroleh, tidak tercapainya nilai penjualan roti dengan target nilai penjualan yang ditetapkan CV Jaya Bakery Bandar Lampung selama tahun 2014-2018.

Tabel 1.3

Target Nilai Penjualan dan

Realisasi Nilai Penjualan Roti yang disalurkan CV Jaya Bakery Bandar Lampung

Tahun 2014-2017.

\begin{tabular}{|c|c|c|c|}
\hline $\begin{array}{c}\text { Tah } \\
\text { un }\end{array}$ & $\begin{array}{c}\text { Target } \\
\text { Nilai } \\
\text { Penjualan } \\
\text { (Rupiah) }\end{array}$ & $\begin{array}{c}\text { Realisasi } \\
\text { Nilai } \\
\text { Penjualan } \\
(\text { Rupiah })\end{array}$ & $\begin{array}{c}\text { Pencap } \\
\text { aian } \\
(\%)\end{array}$ \\
\hline 201 & $\begin{array}{c}3.000 .000 \\
2.000\end{array}$ & $\begin{array}{c}2.645 .300 \\
.000\end{array}$ & 88,17 \\
\hline 201 & 3.000 .000 & 2.350 .150 & \\
5 & .000 & .000 & 78,34 \\
\hline 201 & 3.000 .000 & 2.400 .450 & \\
6 & .000 & .000 & 80,01 \\
\hline 201 & 3.000 .000 & 2.580 .680 & \\
7 & .000 & .000 & 86,02 \\
\hline 201 & 3.000 .000 & 2.644 .000 & \\
8 & .000 & .000 & 88,14 \\
\hline Rata & 3.000 .000 & 2.524 .116 & 84 \\
-rata & .000 & .000 & \\
\hline
\end{tabular}

Sumber: CV Jaya Bakery Bandar Lampung, 2018

Berdasarkan data di atas terlihat pencapaian nilai penjualan barang-barang yang disalurkan oleh CV Jaya Bakery Bandar Lampung belum mencapai target nilai penjualan yang ditetapkan CV Jaya Bakery Bandar Lampung dari tahun 2014 hingga 2018, dimana rata-rata tingkat pencapaian hanya mencapai $84 \%$ dari target yang ditetapkan. 
Berdasarkan uraian diatas maka penulis tertarik untuk melakukan dengan judul penelitian "Pengaruh Motivassi dan
Kompensasi Terhadap Kinerja

Karyawan Pada CV. Jaya Bakery Di Bandar Lampung".

Gambar 2.1 Kerangka Konseptual

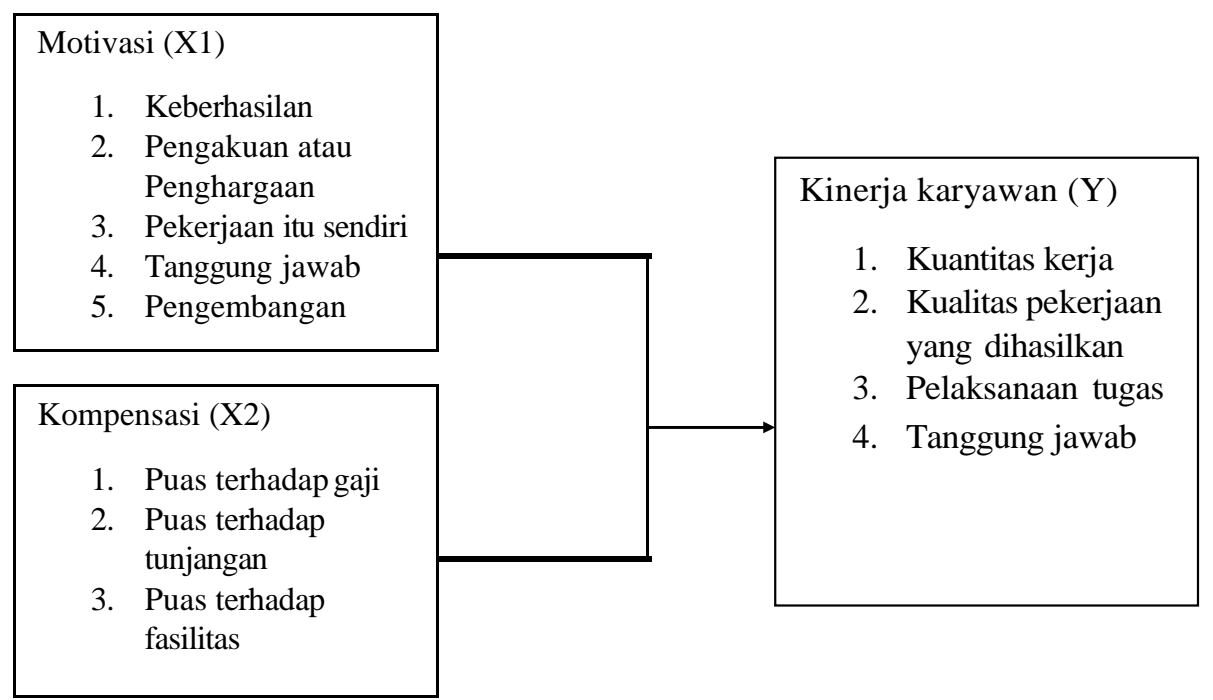

Sumber: Herzberg dikutip oleh Siagian (2008:164), Simamora (2004, p 442), Anwar Prabu Mangkunegara (2009:75)

\section{Hipotesis}

Hipotesis merupakan jawaban sementara terhadap rumusan masalah penelitian, oleh karena itu rumusan masalah penelitian biasanya disusun kalimat pertanyaan hipotesis. Bertolak dari kerangka berfikir yang telah dikemukakan sebagai titik tolak dalam penyusunan hipotesis, maka dapat hipotesis sebagai berikut:

1. Motivasi berpengaruh signifikan terhadap Kinerja Karyawan pada CV. Jaya Bakery di Bandar Lampung.

2. Kompensasi berpengaruh signifikan terhadap Kinerja Karyawan pada CV. Jaya Bakery di Bandar Lampung.

3. Motivasi Dan Kompensasi bersama-sama berpengaruh signifikan Terhadap Kinerja Karyawan CV. Jaya Bakery Bandar Lampung.

\section{METODE PENELITIAN}

\section{Jenis Penelitian} penelitian:

1. Penelitian Lapangan (Field Work Research)

Penelitian yang dilakukan dalam kancah kehidupan yang sebenarnya dengan terjun langsung ke masyarakat atau objek penelitian atau sasaran penelitian untuk menemukan secara spesifik dan realitis tentang sesuatu yang sedang terjadi pada suatu saat ditengah masyarakat.

2. Penelitian Kepustakaan (Library Research)

Penelitian ini dilakukan untuk mengumpulkan data dan informasi dengan bantuan bahan-bahan kepustakaan, berbagai laporan-laporan karangan ilmiah dan sejenisnya yang berhubungan dengan permasalahan yang sedang diteliti. 


\section{Desain Penelitian}

Definisi desain penelitian menurut Moh. Nazir (2003:1) adalah: "semua proses yang diperlukan dalam perencanaan dan pelaksanaan penelitian, mulai tahap persiapan sampai tahap penyusunan laporan". Desain penelitian yang digunakan dalam penelitian ini adalah Deskriptif Regresif dengan tujuan untuk memecahkan atau menjawab permasalahan yang diteliti yaitu Motivasi Dan Kompensasi Terhadap Kinerja Karyawan pada CV. Jaya Bakery yang berdasarkan teori - teori yang terdapat pada BAB II.

\section{Populasi Dan Sampel}

Menurut Riduwan

mengungkapkan populasi merupakan objek atau subjek yang berada pada suatu wilayah dan memenuhi syarat-syarat tertentu berkaitan dengan masalah penelitian. Dalam penelitian ini yang menjadi populasi adalah karyawan $\mathrm{CV}$. Jaya Bakery yang berjumlah 40 orang.

Sedangkan Sampel menurut Riduwan (2013:56) mengemukakan bahwa sampel adalah sebagian dari populasi yang diambil sebagai sumber data dan dapat mewakili seluruh populasi. Melihat jumlah karyawan pada CV. Jaya Bakery kurang dari 100 orang, maka yang dijadikan sampel adalah seluruh karyawan populasi atau karyawan CV. Jaya Bakery yaitu sebanyak 40 orang.

\section{Teknik Pengumpulan Data}

Teknik pengumpulan data yang dilakukan dalam penelitian ini adalah:

1. Observasi

Observasi merupakan teknik yang digunakan untuk pengumpulan data dengan melakukan pengamatan dan pencatatan secara sistematik terhadap gejala atau variable yang tampak pada objek penelitian.

2. Wawancara

Teknik pengumpulan data yang dilakukan dengan mengadakan tanya jawab langsung dengan responden dan pihak-pihak yang ada kaitannya dengan masalah yang akan diteliti.

3. Dokumentasi

Dokumentasi merupakan teknik pengumpulan data yang dilakukan dengan menggunakan dokumen tertulis (hasil penelitian, laporan tertulis, literature, majalah, jurnal, internet, dan sebagainya) sebagai sumber data penelitian dengan cara melekukan pengelompokan atau klasifikasi data secara sistematis yang berhubungan denga masalah penelitian. Teknik yang digunakan yaitu dokumentasi dengan cara meminta data-data yang diperlukan kepada perusahaan CV. Jaya Bakery melalui dokumetasi yang berhubungan langsung pada judul penelitian.

4. Angket (Questionnaire)

Teknik pengumpulan data dengan menyebarkan daftar pertanyaan yang diberikan kepada responden, dengan harapan mereka bersedia memberikan respon sesuai dengan permintaan peneliti.

\section{Metode Analisis \\ Analisis Data Kualitatif}

Yaitu analisis dimana data yang diperoleh mengenai objek penelitian yang merupakan data kualitatif dianalisisis berdasarkan perbandingan teori dari literatur dengan kenyataan yang diperoleh penulis selama peneltian dilakukan. Dengan metode penelitian yaitu deskriptif untuk melihat atau menggambarkan bagaimana motivasi dan kompensasi dalam upaya mewujudkan kinerja karyawan pada CV. Jaya Bakery Bandar Lampung.

\section{Analisis Data Kuantitatif}

Yaitu dengan melakukan pengolahan data dengan menggunakan rumus-rumus atau metode statistik untuk mempermudah analisisis data maka dalam penelitian ini menggunakan Software SPSS 17. 


\section{Analisis Kuantitatif}

\section{Regresi Linier Berganda}

Analisis Inferensial dimaksudkan untuk mengetahui besarnya pengaruh variabel bebas terhadap variabel terikat yaitu dengan menggunakan analisis regresi linier berganda. Dari hasil pengolahan data dengan menngunakan program komputer SPSS versi 17 yaitu pada lampiran diperoleh hasil sebagai berikut:

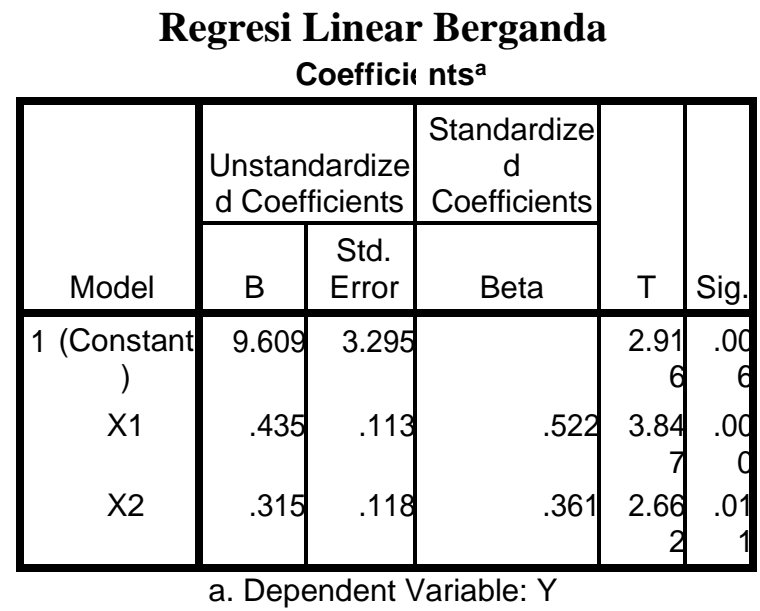

Berdasarkan persamaan regresi linear berganda seperti diatas dapat diberikan interprestasi sebagai berikut :

a. Hasil diatas dapat dinyatakan dalam bentuk persamaan $\mathrm{Y}=9,609$ $+0,435 \mathrm{X} 1+0,315 \mathrm{X} 2$ yang dapat diinterpretasikan sebagai berikut, Persamaan $\mathrm{Y}=9,609+0,435 \mathrm{X} 1+$ 0,315X2 mengindikasikan bahwa koefisien variabel Motivasi $(0,435)$ mempunyai nilai lebih besar dari pada nilai koefisien variabel Kompensasi $(0,315)$.

b. Nilai koefisien untuk variabel Motivasi $\left(\mathrm{X}_{1}\right)$ sebesar 0,435 mengandung arti bahwa terdapat pengaruh positif antara variabel Motivasi $\left(\mathrm{X}_{1}\right)$ terhadap variabel Kinerja Karyawan (Y), dengan demikian jika $\left(\mathrm{X}_{1}\right)$ ditingkatkan sebesar $1 \%$ sementara Kompensasi dianggap tetap maka Kinerja Karyawan meningkat $4.35 \%$.

c. Nilai koefisien untuk variabel Kompensasi $\left(\mathrm{X}_{2}\right)$ sebesar 0,315 mengandung arti bahwa terdapat pengaruh positif antara variable Kompensasi $\left(\mathrm{X}_{2}\right)$ terhadap variabel Kinerja Karyawan (Y), dengan demikian jika $\left(\mathrm{X}_{2}\right)$ ditingkatkan sebesar $1 \%$ sementara Motivasi dianggap tetap maka kinerja karyawan meningkat $3.15 \%$.

d. Maka dapat di simpulkan dari kedua variabel tersebut menunjukkan bahwa terjadinya Kinerja Karyawan yang baik lebih banyak atau lebih dominan dipengaruhi oleh Motivasi dari pada Kompensasi.

\section{Uji Hipotesis}

\section{Uji t secara parsial}

Pengujian hipotesis secara parsial dapat dilakukan untuk mengetahui pengaruh masing-masing variabel bebas terhadap variabel terikat, jika nilai sig $<0,05$ maka hipotesis yang diujikan diterima atau Ho ditolak dan Ha diterima.

\section{Uji Hipotesis Secara Parsial (Uji t)}

\begin{tabular}{|c|c|c|c|c|}
\hline $\begin{array}{l}\text { Penga } \\
\text { ruh }\end{array}$ & $\begin{array}{c}\mathbf{t}_{\text {hitu }} \\
\mathbf{n g}\end{array}$ & $\begin{array}{c}t_{\text {tabel }}( \\
n- \\
2 ; \alpha 0, \\
05)\end{array}$ & $\begin{array}{c}\text { Kond } \\
\text { isi }\end{array}$ & $\begin{array}{c}\text { Kesimp } \\
\text { ulan }\end{array}$ \\
\hline $\begin{array}{c}\mathrm{X}_{1} \mathrm{ke} \\
\mathrm{Y}\end{array}$ & $\begin{array}{l}3.8 \\
47\end{array}$ & 2.026 & $\begin{array}{c}\mathrm{t}_{\text {hitung }} \\
<\mathrm{t}_{\text {tabel }} \\
(0,00 \\
0< \\
0,05)\end{array}$ & $\begin{array}{c}\text { Ho } \\
\text { ditolak } \\
\text { dan } \mathrm{Ha} \\
\text { diterima }\end{array}$ \\
\hline $\begin{array}{c}\mathrm{X}_{2} \mathrm{ke} \\
\mathrm{Y}\end{array}$ & $\begin{array}{l}2.6 \\
62\end{array}$ & 2.026 & $\begin{array}{c}\mathrm{t}_{\text {hitung }} \\
<\mathrm{t}_{\text {tabel }} \\
(0,01 \\
1< \\
0,05)\end{array}$ & $\begin{array}{c}\text { Ho } \\
\text { ditolak } \\
\text { dan } \mathrm{Ha} \\
\text { diterima }\end{array}$ \\
\hline
\end{tabular}

Sumber: Data Diolah, 2018

1. Variabel Motivasi $\left(\mathrm{X}_{1}\right)$ terhadap Kinerja Karyawan (Y)

Untuk variabel Motivasi diperoleh nilai thitung sebesar 3.847 lebih besar dari nilai $t_{\text {tabel }} 2.026$ atau dengan kata lain $t_{\text {hitung }}>t_{\text {tabel}}$, sedangkan hasil significant yang diperoleh sebesar 0,000 , lebih kecil dari $\alpha$ 
yang ditentukan yaitu 0,05 sehingga dapat dikatakan significant. Dengan demikian, Ho ditolak dan $\mathrm{Ha}$ diterima, atau dengan kata lain: Hipotesis pertama: Motivasi berpengaruh positif dan signifikan terhadap Kinerja Karyawan pada CV Jaya Bakery di Bandar Lampung, terbukti dan dapat diterima kebenarannya.

2. Variabel Kompensasi $\left(\mathrm{X}_{2}\right)$ terhadap Kinerja Karyawan(Y)

Untuk variabel Kompensasi diperoleh nilai $t_{\text {hitung }}$ sebesar 2.662 lebih besar dari nilai $t_{\text {tabel }} 2.026$ atau dengan kata lain $t_{\text {hitung }}>t_{\text {tabel }}$, sedangkan hasil significant yang diperoleh sebesar 0,011, lebih kecil dari $\alpha$ yang ditentukan yaitu 0,05 sehingga dapat dikatakan significant. Dengan demikian, Ho ditolak dan $\mathrm{Ha}$ diterima, atau dengan kata lain: Hipotesis kedua: Kompensasi berpengaruh positif dan signifikan terhadap Kinerja Karyawan pada CV Jaya Bakery di Bandar Lampung, terbukti dan dapat diterima kebenarannya.

\section{Uji Hipotesis Anova atau Uji F}

\section{Uji Hipotesis Anova (Uji F)} ANOVA $^{\mathrm{D}}$

\begin{tabular}{|c|r|r|r|r|r|}
\hline Model & $\begin{array}{c}\text { Sum of } \\
\text { Squares }\end{array}$ & df & $\begin{array}{c}\text { Mean } \\
\text { Square }\end{array}$ & F & Sig. \\
\hline 1 Regression & 932.379 & 2 & 466.190 & 38.917 & .0002 \\
Residual & 443.221 & 37 & 11.979 & & \\
Total & 1375.600 & 39 & & & \\
\hline
\end{tabular}

a. Predictors: (Constant), X2, X1

b. Dependent Variable: $Y$
Untuk pengujian secara simultan diperoleh nilai $F_{\text {hitung }}(38,917)>F_{\text {tabel }}(3,32)$ dengan nilai signifikansi (sig.) $0,000<\alpha \quad 0,05$, sehingga Ho ditolak dan Ha diterima yang berarti secara bersama-sama Motivasi $\left(X_{1}\right)$ dan Kompensasi $\left(\mathrm{X}_{2}\right)$ berpengaruh positif dan signifikan terhadap Kinerja Karyawan (Y) pada CV Jaya Bakery di Bandar Lampung.

Hipotesis ketiga: Motivasi dan Kompensasi secara bersama-sama berpengaruh positif dan signifikan terhadap Kinerja Karyawan pada CV Jaya Bakery di Bandar Lampung, terbukti dan dapat diterima kebenarannya.

\section{Koefisien determinasi $\left(\mathbf{R}^{\mathbf{2}}\right)$}

Koefisien determinasi ini digunakan untuk mengetahui seberapa besar pengaruh variabel-variabel bebas memiliki pengaruh terhadap variabel terikatnya. Nilai koefisien determinasi ditentukan dengan nilai adjusted $\mathrm{R}$ square.

\section{Koefisien Determinasi Model Summary}

\begin{tabular}{|c|c|r|r|r|}
\hline Mode & \multicolumn{1}{|c|}{$\mathrm{R}$} & $\begin{array}{c}\mathrm{R} \\
\text { Square }\end{array}$ & $\begin{array}{l}\text { Adjusted R } \\
\text { Square }\end{array}$ & $\begin{array}{r}\text { Std. Error of } \\
\text { the Estimate }\end{array}$ \\
\hline 1 & $.773^{\mathrm{a}}$ & .598 & .586 & 3.430 \\
\hline
\end{tabular}

a. Predictors: (Constant), Kompensasi, Motivasi

Hasil perhitungan regresi dapat diketahui bahwa koefisien determinasi ( $\mathrm{R}$ Square) yang diperoleh sebesar 0,598. Hal ini berarti 59,8\% Kinerja Karyawan pada CV Jaya Bakery di Bandar Lampung dipengaruhi oleh faktor Motivasi dan Kompensasi, sedangkan sisanya yaitu $44,2 \%$ dipengaruhi oleh variabel-variabel lainnya yang tidak diteliti dalam penelitian ini.

1. Berdasarkan hasil dari analisis kuantitatif dengan uji t hitung lebih besar dibandingkan t tabel variabel Motivasi berpengaruh positif dan signifikan terhadap Kinerja

\section{KESIMPULAN DAN SARAN Kesimpulan}

Dari pembahasan dan analisis data yang telah diuraikan, maka dapat ditarik kesimpulan sebagai berikut: 
Karyawan pada CV Jaya Bakery di Bandar Lampung

2. Berdasarkan hasil dari analisis kuantitatif dngan uji t hitung lebih besar dibandingkan $\mathrm{t}$ tabel Kompensasi berpengaruh positif dan signifikan terhadap Kinerja Karyawan pada CV Jaya Bakery di Bandar Lampung.

3. Berdasarkan analisis kuantitatif dengan pengujian $\mathrm{F}$ hitung lebih besar dibandingkan dengan $\mathrm{F}$ tabel variabel Motivasi dan kompensasi secara bersama-sama berpengaruh signifikan terhadap Kinerja Karyawan pada CV Jaya Bakery di Saran Bandar Lampung.

Berdasarkan kesimpulan yang telah dilakukan dan dari hasil koesioner maka saran yang dapat diberikan dalam penelitian ini yaitu:

1. Perlu ditingkatkannya motivasi yang di berikan pemimpin kepada karyawan agar semangat bekerja. Maka dari itu diharapkan bagi CV Jaya Bakery di Bandar Lampung agar lebih intensif dalam memberikan motivasi yang baik agar dapat meningkatkan motivasi serta meningkatkan kinerja karyawan.

2. Berikutnya perlu ditingkatkannya kompensasi yang ada agar karyawan merasa dihargai, dengan meningkatnya kompensasi akan meningkatkan perilaku karyawan menjadi perilaku yang lebih baik dan tepat waktu dalam bekerja. Maka itu harus perlu ditingkatkan kompensasi pada CV Jaya Bakery di Bandar Lampung agar kinerja karyawan meningkat.

3. CV Jaya Bakery di Bandar Lampung lebih memperhatikan pemberian bonus kerja yang diberikan kepada karyawan agar kinerja karyawan yang bekerja di cv jaya bakery ini lebih baik yang sesuai dengan apa yang diharapkan perusahaan.

\section{DAFTAR PUSTAKA}

Ambar Teguh Sulistiyani dan Rosidah. (2003). Manajemen Sumber Daya Manusia. Yogyakarta: Graha Ilmu.

Bohlander dan Snell. (2010). Principles of Human Resource Management, edisi15. Nelson Education, Canada

Bangun, Wilson. 2012. "Manajemen Sumber Daya Manusia". Erlangga, Jakarta. Dessler, Gary. 2010. Manajemen Sumber Daya Manusia, Jakarta: PT. Indeks 2007. Manajemen Sumber Daya Manusia. Edisi Kesepuluh. Jilid 2. Jakarta: PT. indeks

Ghozali, Imam. 2009. Aplikasi Analisis Multivariate Dengan Program SPSS. Edisi Keempat. Penerbit Universitas Diponegoro: Jawa Tengah.
George, J. M., \& Jones, G (2005). Understanding and Managing Organizational Behavior. New Jersey: Upper Saddle River 2012.

Understanding and Managing Organizational Behavior. New Jersey: Upper Saddle River

Hartatik, Indah Puji. 2014.
Buku
Praktis
Mengembangkan
SDM. Yogyakarta :
Laksana
Kepemimpinan
Birokrasi Bandung:
CV. Alfabeta

Pasolong, Harbani.2008.

Hasibuan, Malayu. 2012. Manajemen Sumber Daya Manusia. PT. Bumi Aksara, Jakarta 
Hasibuan, Malayu S.P. 2002. Manajemen Sumber Daya Manusia. Jakarta : Bumi Aksara 2009.

Manajemen Sumber

Daya Manusia.

Jakarta : Bumi

Aksara.

Handoko, T. Hani. 2011. Manajemen Personalia dan Sumberdaya Manusia. Yoygakarta: Penerbit BPFE

2009. Manajemen Sumber Daya Manusia. Cetakan IX Jilid I. Yogjakarta: BPFE

Hariandja , Marihot T.E. 2002. Pengadaan, Pengembangan, Pengkompensasian, dan Peningkatan Produktivas Pegawai. Jakarta: Grasindo

Henry, Simamora, 2004, Manajemen Sumber Daya Manusia, Edisi Ketiga, Yogyakarta, STIE YPKN Herzberg, 1950, A to Z Human Capital Manajemen Sumber Daya Manusia, Jakarta. Kompas Media. 